Louisiana State University

LSU Digital Commons

Faculty Publications

Department of Biological Sciences

6-14-2016

\title{
Use of Protein Cross-Linking and Radiolytic Labeling to Elucidate the Structure of PsbO within Higher-Plant Photosystem II
}

\author{
Manjula P. Mummadisetti \\ Louisiana State University \\ Laurie K. Frankel \\ Louisiana State University \\ Henry D. Bellamy \\ Louisiana State University \\ Larry Sallans \\ University of Cincinnati \\ Jost S. Goettert \\ Louisiana State University
}

See next page for additional authors

Follow this and additional works at: https://digitalcommons.Isu.edu/biosci_pubs

\section{Recommended Citation}

Mummadisetti, M., Frankel, L., Bellamy, H., Sallans, L., Goettert, J., Brylinski, M., \& Bricker, T. (2016). Use of Protein Cross-Linking and Radiolytic Labeling to Elucidate the Structure of PsbO within Higher-Plant Photosystem II. Biochemistry, 55 (23), 3204-3213. https://doi.org/10.1021/acs.biochem.6b00365

This Article is brought to you for free and open access by the Department of Biological Sciences at LSU Digital Commons. It has been accepted for inclusion in Faculty Publications by an authorized administrator of LSU Digital Commons. For more information, please contact ir@lsu.edu. 


\section{Authors}

Manjula P. Mummadisetti, Laurie K. Frankel, Henry D. Bellamy, Larry Sallans, Jost S. Goettert, Michal Brylinski, and Terry M. Bricker 


\title{
Use of Protein Cross-Linking and Radiolytic Labeling To Elucidate the Structure of PsbO within Higher-Plant Photosystem II
}

\author{
Manjula P. Mummadisetti, ${ }^{\dagger}$ Laurie K. Frankel, $^{\dagger}$ Henry D. Bellamy, ${ }^{\dagger}$ Larry Sallans, $^{\S}$ Jost S. Goettert, $^{\ddagger}$ \\ Michal Brylinski, ${ }^{\dagger}$ and Terry M. Bricker, ${ }^{*}$
${ }^{\dagger}$ Division of Biochemistry and Molecular Biology, Department of Biological Sciences, Louisiana State University, Baton Rouge, Louisiana 70803, United States
${ }^{\ddagger}$ The J. Bennett Johnston, Sr. Center for Advanced Microstructures \& Devices, Louisiana State University, Baton Rouge, Louisiana 70806, United States

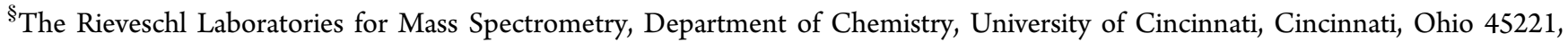 \\ United States
}

ABSTRACT: We have used protein cross-linking with the zero-length crosslinker 1-ethyl-3-(3-dimethylaminopropyl) carbodiimide, and radiolytic footprinting coupled with high-resolution tandem mass spectrometry, to examine the structure of higher-plant PsbO when it is bound to Photosystem II. Twenty intramolecular cross-linked residue pairs were identified. On the basis of this cross-linking data, spinach PsbO was modeled using the Thermosynechococcus vulcanus PsbO structure as a template, with the cross-linking distance constraints incorporated using the MODELLER program. Our model of higher-plant PsbO identifies several differences between the spinach and cyanobacterial proteins. The N-terminal region is particularly interesting, as this region has been suggested to be important for oxygen evolution and for the specific binding of PsbO to Photosystem II. Additionally, using radiolytic mapping, we have identified regions on spinach $\mathrm{PsbO}$ that are shielded from the bulk solvent. These domains may represent regions on PsbO that interact with other components, as yet unidentified, of the photosystem.

$\mathrm{P}$ hotosystem II (PS II) is a light energy-driven waterplastoquinone oxidoreductase. Excitation energy from the light-harvesting apparatus (phycobilisomes in cyanobacteria and light-harvesting chlorophyll proteins in green plants and algae) is transferred to the reaction center of the photosystem. Initial charge separation occurs between $\mathrm{Chl}_{\mathrm{D} 1}$ and $\mathrm{Pheo}_{\mathrm{D} 1}$, which yields $\mathrm{Chl}_{\mathrm{D} 1}{ }^{+} \mathrm{Pheo}_{\mathrm{D} 1}{ }^{-1}$. This charge-separated state is stabilized by rapid electron transfer from Pheo $_{\mathrm{D} 1}{ }^{-}$, first to $\mathrm{Q}_{\mathrm{A}}$ and then to $\mathrm{Q}_{\mathrm{B}}$. The accumulation of two electrons on $\mathrm{Q}_{\mathrm{B}}$ leads to protonation and its subsequent release as plastoquinol. $\mathrm{Chl}_{\mathrm{D} 1}{ }^{+}$is reduced by $\mathrm{P}_{\mathrm{D} 1}$, and $\mathrm{P}_{\mathrm{D} 1}{ }^{+}$is reduced by $\mathrm{Y}_{\mathrm{z}}$, the residue $\mathrm{D} 1:{ }^{161} \mathrm{Y}$, yielding $\mathrm{Y}_{\mathrm{Z}} \bullet$ with the release of a proton. The subsequent reduction of $\mathrm{Y}_{\mathrm{Z}}{ }^{\bullet}$ by the $\mathrm{Mn}_{4} \mathrm{CaO}_{5}$ cluster occurs via protoncoupled electron transport and leads to the accumulation of an oxidizing equivalent at the oxygen-evolving site, the $\mathrm{Mn}_{4} \mathrm{CaO}_{5}$ metal center. The accumulation of four oxidizing equivalents ultimately leads to the oxidation of two water molecules and the release of dioxygen., ${ }^{2,3}$

Cyanobacterial PS II contains at least 20 subunits, of which at least 17 are intrinsic membrane proteins. ${ }^{4}$ A subset of these components (D1, D2, CP43, CP47, the $\alpha$ and $\beta$ subunits of cytochrome $b_{559}$, and the PSBL protein) is required for oxygen evolution and accumulation of the photosystem in thylakoid membranes. Genetic or biochemical removal of any of these protein subunits leads to loss of functional PS II. In addition, 10 low-molecular mass intrinsic proteins are present; however, their functions remain obscure. PS II complexes containing only these intrinsic proteins evolve oxygen at low rates and require very high concentrations of calcium and chloride. ${ }^{5,6}$ At presumptive physiological concentrations of these cofactors, efficient oxygen evolution requires the extrinsic components of the photosystem. These include PsbO, which is uniformly present in all oxygenic organisms, and either PsbU, PsbV, CyanoQ and CyanoP (in the cyanobacteria), or PsbP, PsbQ and PsbR (in green plants) (for reviews, see refs 7-12). PsbO plays an important role in the stabilization of the $\mathrm{Mn}_{4} \mathrm{CaO}_{5}$ cluster ${ }^{13}$ at low chloride concentrations and protects the metal cluster from exogenous reductants. In higher plants, it is required for PS II assembly ${ }^{7,14-17}$ and photosynthetic oxygen evolution. Interestingly, in cyanobacteria, this is not the case. ${ }^{5}$ In the absence of PsbO, Synechocystis can grow autotrophically and evolve oxygen, albeit at lower rates. ${ }^{18}$

Over the past 15 years, increasingly higher resolution crystal structures of thermophilic cyanobacterial PS II have become available. ${ }^{4,19-24}$ These studies have been critically important in improving our understanding of the molecular organization of the photosystem. Recently, a crystal structure of PS II from the red alga Cyanidium caldarium, at $2.76 \AA$ resolution, has also become available. ${ }^{25}$ This is, importantly, the first structure of PS II available from a eukaryote. It should be noted, however, that the red algae do not lie in the green plant lineage.

As no crystal structure for higher-plant PS II is available, the structure and interactions of the extrinsic proteins with the

Received: April 18, 2016

Revised: May 18, 2016

Published: May 20, 2016 
intrinsic components of the photosystem have been modeled by comparison to those of cyanobacterial PS II. It must be stressed, however, that the interactions of the PsbP and PsbQ proteins with PS II are not well understood. Additionally, strong biochemical evidence indicates the presence of a putative second copy of PsbO being associated with each PS II monomer in higher plants (for reviews, see refs 13 and 26). Protein crosslinking coupled with tandem mass spectrometry is a powerful technique for elucidating protein-protein interactions in multisubunit protein complexes. ${ }^{27,28}$ Recently, these methods have been used to investigate subunit-subunit interactions within PS II and PS I. ${ }^{29-32}$ Liu et al. ${ }^{30}$ elucidated the structure of a PS II-phycobilisome-PS I megacomplex using dithiobis(succinimidylpropionate). Liu et al., ${ }^{31}$ using the cross-linkers 1-ethyl-3-(3-dimethylaminopropyl) carbodiimide (EDC, a zerolength cross-linker) and dithiobis(succinimidylpropionate), identified a binding domain for CyanoQ within Synechocystis PS II. Ido et al. ${ }^{32}$ have extended their earlier studies using the cross-linker EDC on higher-plant PS II. In this study, they identified interchain cross-linked products involving PsbP, PsbQ and other PS II components (CP43, CP26, and PsbR). Ido et $\mathrm{al}^{32}$ have positioned PsbQ on the periphery of the PS II complex in marked contrast to the position of CyanoQ proposed by Liu et al. ${ }^{31}$ Our laboratory has used the cross-linker bis-sulfosuccinimidyl suberate to examine the interaction of PsbP and PsbQ in higher-plant PS II. ${ }^{33}$ Our results indicate that PsbP and PsbQ directly interact, with the location of PsbQ being consistent with the location hypothesized by either Liu et al. ${ }^{31}$ or Ido et al. ${ }^{32}$ It should be noted that the proposed location of PsbQ presented by Ido et al. ${ }^{32}$ and modified by Mummadisetti et al. ${ }^{33}$ is similar to the location of PsbQ' in the Cyanidium PS II crystal structure. $^{25}$ Recently, models for the structural organization of the higher-plant extrinsic proteins in association with PS II have been presented. ${ }^{12}$

The radiolysis of water by synchrotron radiation produces $\bullet \mathrm{OH}$, which is capable of oxidatively modifying amino acid residues that are in contact with the bulk solvent. The modified residues can be identified using tandem mass spectrometry, and their location can be used to "footprint" protein-protein interactions within multisubunit protein complexes. ${ }^{34-36}$ This radiolytic mapping technique has been used to identify both surface and buried amino acid residues that are exposed to water. ${ }^{37-40}$ Recently, we used this technique to examine the interaction of PsbP and PsbQ in higher-plant PS II. ${ }^{33}$ In this study, we identified domains on PsbP that appear to be shielded from the bulk solvent by intrinsic components of PS II and, possibly, by PsbR.

In this paper, we have used protein cross-linking coupled with tandem mass spectrometry to identify 20 intramolecular crosslinked products within the PsbO protein. These experiments allowed the modeling of the N-terminus of higher-plant PsbO, which contains a 10 -amino acid extension when compared to cyanobacterial PsbO. This facilitated the localization of the two binding determinants for higher-plant PsbO that previously had been identified in this region. ${ }^{41,42}$ Radiolytic mapping was also used to oxidatively modify surface residues on PsbO that were in contact with water. Seventy-seven residues were identified. Interestingly, a large domain on the surface of PsbO was resistant to radiolytic modification, indicating that it was shielded from the bulk solvent. This domain appears to define buried regions of PsbO that are in contact with other, as yet unidentified, components of PS II.

\section{MATERIALS AND METHODS}

PS II Membrane Isolation and Protein Cross-Linking. PS II membranes were isolated by the method of Berthold et al. ${ }^{43}$ from market spinach. Chl was determined by the method of Arnon. ${ }^{44}$ After isolation, the PS II membranes were suspended at a concentration of $2 \mathrm{mg}$ of chl/mL in $50 \mathrm{mM}$ Mes- $\mathrm{NaOH}$ ( $\mathrm{pH}$ 6.0), $300 \mathrm{mM}$ sucrose, $15 \mathrm{mM} \mathrm{NaCl}$ (SMN) buffer and frozen at $-80{ }^{\circ} \mathrm{C}$ until they were used. Protein cross-linking was performed using the zero-length cross-linker EDC. In our experiments, PS II membranes were suspended at a chl concentration of $200 \mu \mathrm{g} / \mathrm{mL}$ in $25 \%$ glycerol, $10 \mathrm{mM} \mathrm{MgCl}_{2}, 5 \mathrm{mM} \mathrm{CaCl}_{2}$, and $50 \mathrm{mM}$ MES-NaOH (pH 6.0) buffer. The membranes were then treated with $6.25 \mathrm{mM}$ EDC and $5 \mathrm{mM} \mathrm{N}$-hydroxysulfosuccinimide for $2 \mathrm{~h}$ at room temperature in the dark. The reaction was quenched by bringing the reaction mixture to $100 \mathrm{mM}$ ammonium bicarbonate and incubating the mixture for $20 \mathrm{~min}$ at room temperature. The membranes were harvested by centrifugation for $25 \mathrm{~min}$ at $38000 \mathrm{~g}$, and the final pellet was resuspended in $1.0 \mathrm{M} \mathrm{NaCl}$ in $\mathrm{SMN}$ buffer for $1 \mathrm{~h}$ at $4{ }^{\circ} \mathrm{C}$ to release the PsbP and PsbQ subunits. The PsbP- and PsbQdepleted PS II membranes were washed with SMN and then treated with $1.0 \mathrm{M} \mathrm{CaCl}_{2}$ in $\mathrm{SMN}$ buffer to release PsbO. After centrifugation to remove the PsbO-depleted membranes, the supernatant from the $\mathrm{CaCl}_{2}$ wash (which contains $\mathrm{PsbO}$ ) was dialyzed overnight against $10 \mathrm{mM}$ Mes- $\mathrm{NaOH}$ ( $\mathrm{pH}$ 6.0) using a $6-8 \mathrm{kDa}$ cutoff membrane (Spectrum Laboratories, Inc.) and was concentrated by ultrafiltration using a $10 \mathrm{kDa}$ cutoff membrane (Millipore Co.). Prior to electrophoresis, protein concentrations were determined using the BCA protein assay. ${ }^{45}$

Synchrotron Radiolysis. Synchrotron radiolysis was performed as described previously. ${ }^{40}$ Radiolysis was performed on the XLRM2 beamline at The J. Bennett Johnston, Sr. Center for Advanced Microstructures \& Devices (CAMD) synchrotron. PS II membranes $(200 \mu \mathrm{L}$ at $2 \mathrm{mg}$ of $\mathrm{chl} / \mathrm{mL})$ were exposed for various lengths of time at room temperature in a multichannel Plexiglas chamber. After exposure, the samples were immediately removed from the chamber and held on ice until being stored at $-80{ }^{\circ} \mathrm{C}$.

Electrophoresis and Protein Digestion. For the EDC cross-linking experiments, the protein samples were resolved on 12.5 to $20 \%$ LiDS-PAGE gradient gels ${ }^{46}$ using ammonium persulfate and tetramethylethylenediamine for polymerization. For the radiolytic experiments, however, the proteins were separated on 12.5 to $20 \%$ acrylamide LiDS-PAGE gradient gels using a nonoxidizing system in which the gels were polymerized with riboflavin (in the presence of diphenyliodonium chloride and toluene sulfinate) by exposure to UV light. ${ }^{47,48}$ The upper reservoir also contained thioglycolate. This was required, as standard PAGE polymerization conditions are known to introduce numerous protein oxidation artifacts. ${ }^{49}$ Earlier experiments indicated that PS II proteins resolved in the nonoxidizing gel system exhibited much lower levels of artifactual protein oxidation than when resolved using standard LiDS-PAGE (see Figure S1 of ref 48).

After electrophoresis, the gels were stained with Coomassie Blue and destained, and protein bands of interest were excised. The protein bands were processed for protease digestion (trypsin or trypsin with Lys-C) using standard protocols. After digestion, the proteolytic peptides were processed using a C18 ZipTip prior to mass analysis.

Mass Spectrometry. The proteolytic peptides were resolved using reversed-phase chromatography with mass spectrometry 
being performed on a Thermo Scientific LTQ-FT instrument. ${ }^{48}$ This is a hybrid instrument consisting of a linear ion trap coupled to a Fourier transform ion cyclotron resonance mass spectrometer.

Identification and analysis of peptides containing cross-linked products or oxidative mass modifications were performed using the MassMatrix online search engine. ${ }^{50,51}$ A FASTA library containing PsbO, PsbP, and PsbQ proteins was searched, as was a decoy library containing the same proteins but with reversed amino acid sequences. For the identification of cross-linked products, peptides were selected if their $\mathrm{P}$ value was $\leq 0.0001$. In this study, as expected, no cross-linked products involving the PsbP and PsbQ proteins were identified. Additionally, crosslinked products were identified with StavroX version 3.4.12 using the same FASTA library. This program reports a nonprobabilistic score and a false discovery rate (FDR) for each identified cross-linked product. The FDR corresponded to 5\%. Only putative cross-linked products that exhibited scores of $>100$ (which was considered a "significant" score ${ }^{52}$ ) and also exhibited scores $>3$ times the FDR were considered in our study. In both MassMatrix and StavroX, a precursor ion precision of $\leq 5.0 \mathrm{ppm}$ was required.

For the radiolytic footprinting studies, MassMatrix was programmed to search for all of the possible oxidative modifications for the 18 modifiable and identifiable amino acids, excluding glycine and alanine. ${ }^{36,53}$ For the identification of oxidative modifications, a more stringent $P$ value $(\leq 0.00001)$ was used. We feel that given the smaller mass modifications introduced by oxidative labeling (2-48 au), the use of a more stringent $P$ value was prudent. For both the protein cross-linking studies and the radiolytic modification experiments, the peptides were required to exhibit $0 \%$ hits to the decoy library for further consideration.

Protein Modeling. Clustal Omega ${ }^{54}$ was used to align the spinach and Thermosynechococcus vulcanus PsbO protein sequences. On the basis of this alignment, the spinach sequence was threaded using SWISS-MODEL ${ }^{55}$ with the structure of T. vulcanus PsbO [contained in Protein Data Bank (PDB) entry $3 \mathrm{WU} 2$, which is the update of PDB entry $3 \mathrm{ARC}^{4}$ ] as a template. Secondary structure prediction for higher-plant $\mathrm{PsbO}$ was performed using Genesilico Metaserver. ${ }^{56}$ The cross-linking distance constraints imposed by the 20 identified EDC crosslinked products were incorporated into the threaded structure using MODELLER. ${ }^{57}$ EDC generates an amide bond between primary amino groups and carboxylates that are in van der Waals contact. $^{58,59}$ To model these interactions, a $\mathrm{C}_{\alpha}-\mathrm{C}_{\alpha}$ distance of 12.1 $\AA^{60,61}$ was used. This distance conservatively takes into account the length of the amino acid $\mathrm{R}$ groups and dynamic variations in the protein structure. The 10 lowest-energy models were analyzed by Ramachandran analysis using PROCHECK ${ }^{62}$ and RAMPAGE. ${ }^{63}$

Antibodies. The antiserum against $\mathrm{PsbO}$ was produced using a synthesized peptide consisting of the $\mathrm{N}$-terminal 27 amino acid residues of the mature spinach protein coupled to keyhole limpet hemocyanin. The antiserum was produced and isolated from rabbits after their immunization by standard protocols. ${ }^{64}$ The specificity of the antiserum was confirmed by its specific reaction with the antigenic peptide, isolated PsbO, PS II membrane preparations, and thylakoid membranes.

\section{RESULTS AND DISCUSSION}

Protein Cross-Linking. Figure 1 illustrates the results obtained upon treatment of PS II membranes with the crosslinker EDC followed by LiDS-PAGE and immunoblotting.

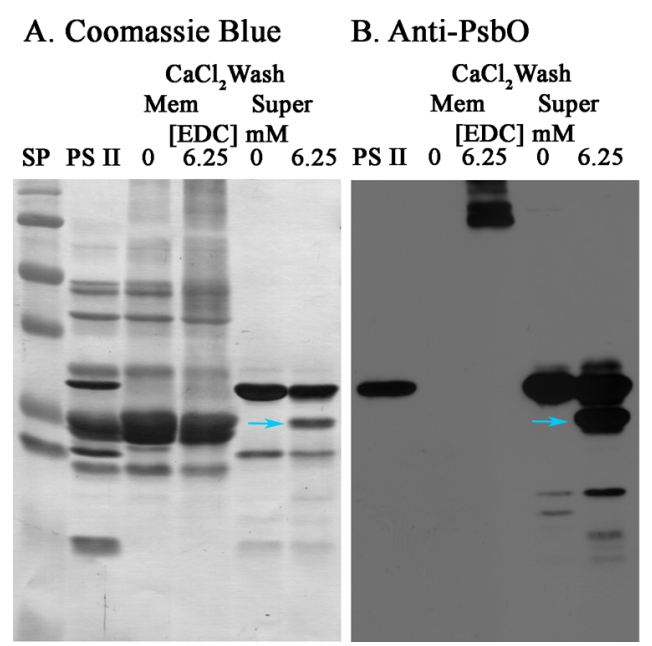

Figure 1. EDC cross-linking of PsbO within the PSII complex. Protein cross-linking was performed as described in Materials and Methods. Illustrated are "Western" blots from the extracts of $1.0 \mathrm{M} \mathrm{CaCl}_{2}$-washed PSII membranes (which were obtained after initially washing with $1.0 \mathrm{M}$ $\mathrm{NaCl}$ ) cross-linked with EDC. Panel A was stained with Coomassie blue, and panel B was probed with anti-PsbO. Intact PS II membranes are labeled PS II and are included for reference. The putative PsbO intramolecular cross-linked product is indicated by the cyan arrows and has an apparent molecular mass of $25 \mathrm{kDa}$. This protein is the subject of our cross-linking study.

After protein cross-linking, the PS II membranes were washed with $\mathrm{NaCl}$ to remove the PsbP and PsbQ proteins. These membranes were then washed with $\mathrm{CaCl}_{2}$ to remove both unmodified $\mathrm{PsbO}$ and $\mathrm{PsbO}$ containing putative intramolecular cross-linked residues. This sample was then dialyzed and concentrated by ultrafiltration. As expected, in the absence of EDC, no cross-linked products were observed for PsbO. After cross-linking with EDC, a variety of cross-linked products containing PsbO were observed. Some of these remained associated with the PS II membranes after sequential washing with $1.0 \mathrm{M} \mathrm{NaCl}$, which removes PsbP and PsbQ from the PS II membranes [no cross-linked products containing either PsbP or PsbQ were observed (data not shown)], and then washing with 1.0 $\mathrm{M} \mathrm{CaCl}_{2}$. These high-apparent molecular mass components represent intermolecular cross-linked products containing $\mathrm{PsbO}$ and intrinsic membrane protein components ${ }^{65,66}$ and are the object of continuing investigations. The $\mathrm{CaCl}_{2}$ treatment removed un-cross-linked $\mathrm{PsbO}$, which migrated at an apparent molecular mass of $29.6 \mathrm{kDa}$, and $\mathrm{PsbO}$, which contained putative intramolecular cross-links, as indicated by more rapid migration via LiDS-PAGE, exhibiting an apparent molecular mass of $25 \mathrm{kDa}$. This protein band reacted only with anti-PsbO and not anti-PsbP or PsbQ (data not shown). This $25 \mathrm{kDa}$ protein is the object of this work.

The observed $25 \mathrm{kDa}$ band could be the result of either proteolysis or intrachain protein cross-linking. Subsequent tandem mass spectrometry indicated no proteolysis was evident as we obtained $100 \%$ coverage for $\mathrm{PsbO}$, with complete coverage of the $\mathrm{N}$ - and C-termini. Consequently, the $25 \mathrm{kDa}$ band appears to result from internal cross-linking with EDC.

In-gel proteolysis followed by tandem mass spectrometry allowed the identification of the cross-linked residues in this $25 \mathrm{kDa}$ band (Table 1). Twenty intrachain cross-linked products were identified within PsbO. All of the cross-linked peptides identified exhibited low $P$ values (the probability that the peptide match is a random occurrence) ranging from $1 \times 10^{-4}$ to 
Table 1. EDC-Cross-Linked Residues Identified in PS II-Bound Spinach PsbO ${ }^{a}$

\begin{tabular}{|c|c|c|c|c|c|}
\hline higher-plant PsbO cross-linked residues & $\begin{array}{l}\text { precursor mass } \\
\text { precision }(\mathrm{ppm})\end{array}$ & StavroX ${ }^{b}$ score & $\mathrm{FDR}^{c}$ & $\begin{array}{l}\text { MassMatrix }^{d} \\
P \text { value }\end{array}$ & $\begin{array}{l}\text { crystal structure distance } e^{e} \\
\qquad\left(\mathrm{C}_{\alpha}-\mathrm{C}_{\alpha}\right)(\AA)\end{array}$ \\
\hline${ }^{4} \mathrm{~K}-{ }^{32} \mathrm{E}:{ }^{1} \mathrm{EGG}[\mathrm{K}]{ }^{7} \mathrm{R}{ }^{21} \mathrm{GTGTANQCPTV}[\mathrm{E}] \mathrm{GGVDSFAFKPG}{ }^{44} \mathrm{~K}$ & -2.1 & - & - & $5.0 \times 10^{-5}$ & $\mathrm{NA}^{f}$ \\
\hline${ }^{4} \mathrm{~K}-{ }^{36} \mathrm{D}:{ }^{1} \mathrm{EGG}[\mathrm{K}]{ }^{7} \mathrm{R}{ }^{21} \mathrm{GTGTANQCPTVEGGV}[\mathrm{D}] \mathrm{SFAFKPG}{ }^{44} \mathrm{~K}$ & -3.7 & - & - & $6.3 \times 10^{-5}$ & $\mathrm{NA}^{f}$ \\
\hline${ }^{9} \mathrm{D}-{ }^{14} \mathrm{~K}:{ }^{6} \mathrm{LTY}[\mathrm{D}] \mathrm{EIQS}[\mathrm{K}] \mathrm{TYLEV}^{20} \mathrm{~K}$ & +0.7 & 172 & 52 & $5.0 \times 10^{-7}$ & $\mathrm{NA}^{f}$ \\
\hline${ }^{10} \mathrm{E}-{ }^{14} \mathrm{~K}:{ }^{6} \mathrm{LTYD}[\mathrm{E}] \mathrm{IQS}[\mathrm{K}] \mathrm{TYLEV}^{20} \mathrm{~K}$ & +0.3 & 182 & 52 & $3.1 \times 10^{-5}$ & $\mathrm{NA}^{f}$ \\
\hline${ }^{14} \mathrm{~K}-{ }^{18} \mathrm{E}:{ }^{6} \mathrm{LTYDEIQS}[\mathrm{K}] \mathrm{TYL}[\mathrm{E}] \mathrm{V}^{20} \mathrm{~K}$ & -0.9 & 253 & 39 & $2.5 \times 10^{-7}$ & 8.1 \\
\hline${ }^{60} \mathrm{~K}-{ }^{62} \mathrm{E}:{ }^{57} \mathrm{FAV}[\mathrm{K}] \mathrm{A}[\mathrm{E}] \mathrm{GIS}{ }^{66} \mathrm{~K}$ & 0.0 & - & - & $1.0 \times 10^{-8}$ & 5.8 \\
\hline${ }^{60} \mathrm{~K}-{ }^{234} \mathrm{D}:{ }^{57} \mathrm{FAV}[\mathrm{K}] \mathrm{AEGIS}{ }^{66} \mathrm{~K}{ }^{234}[\mathrm{D}] \mathrm{V}^{236} \mathrm{~K}$ & +0.5 & 278 & 39 & $2.5 \times 10^{-9}$ & 6.9 \\
\hline${ }^{62} \mathrm{E}-{ }^{66} \mathrm{~K}:{ }^{61} \mathrm{~A}[\mathrm{E}] \mathrm{GIS}[\mathrm{K}] \mathrm{NSGPDFQNT}{ }^{66} \mathrm{~K}$ & +1.0 & - & - & $1.2 \times 10^{-8}$ & 11.5 \\
\hline${ }^{62} \mathrm{E}-{ }^{233} \mathrm{~K}:{ }^{61} \mathrm{~A}[\mathrm{E}] \mathrm{GIS}^{66} \mathrm{~K}{ }^{231} \mathrm{VP}[\mathrm{K}] \mathrm{DV}^{236} \mathrm{~K}$ & 0.0 & - & - & $5.0 \times 10^{-7}$ & 9.9 \\
\hline${ }^{66} \mathrm{~K}-{ }^{71} \mathrm{D}:{ }^{61} \mathrm{AEGIS}[\mathrm{K}] \mathrm{NSGP}[\mathrm{D}] \mathrm{FQNT}{ }^{66} \mathrm{~K}$ & -2.2 & - & - & $6.3 \times 10^{-7}$ & 10.8 \\
\hline${ }^{66} \mathrm{~K}-{ }^{234} \mathrm{D}:{ }^{61} \mathrm{AEGIS}[\mathrm{K}] \mathrm{NSGPDFQNT}{ }^{76} \mathrm{~K}{ }^{234}[\mathrm{D}] \mathrm{V}^{236} \mathrm{~K}$ & -2.6 & - & - & $5.0 \times 10^{-9}$ & 16.1 \\
\hline${ }^{97} \mathrm{D}-{ }^{101} \mathrm{~K}:{ }^{81}$ LTYTLDEIEGPFEVSS[D]GTV[K]FEE ${ }^{105} \mathrm{~K}$ & -4.8 & 183 & 59 & $6.3 \times 10^{-8}$ & 9.5 \\
\hline $\begin{array}{l}\left.{ }^{97} \mathrm{D}-{ }^{105} \mathrm{~K}:{ }^{81} \text { LTYTLDEIEGPFEVSS[D }\right] \mathrm{GTV}^{101} \mathrm{~K}{ }^{102} \mathrm{FEE}[\mathrm{K}] \\
\text { DGIDYAAVTVQLPGGE }{ }^{122} \mathrm{R}\end{array}$ & +0.1 & 264 & 39 & - & 22.9 \\
\hline${ }^{101} \mathrm{~K}-{ }^{104} \mathrm{E}:{ }^{81}$ LTYTLDEIEGPFEVSSDGTV $[\mathrm{K}] \mathrm{FE}[\mathrm{E}]{ }^{105} \mathrm{~K}$ & -4.8 & - & - & $1.0 \times 10^{-10}$ & 9.7 \\
\hline $\begin{array}{l}{ }^{101} \mathrm{~K}-{ }^{109} \mathrm{D}:{ }^{81} \text { LTYTLDEIEGPFEVSSDGTV }[\mathrm{K}] \mathrm{FEE}^{105} \mathrm{~K}{ }^{106} \mathrm{DGI}[\mathrm{D}] \\
\text { YAAVTVQLPGEE }{ }^{122} \mathrm{R}\end{array}$ & +0.11 & 249 & 39 & - & 8.6 \\
\hline${ }^{103} \mathrm{E}-{ }^{105} \mathrm{~K}:{ }^{102} \mathrm{~F}[\mathrm{E}] \mathrm{E}[\mathrm{K}]$ DGIDYAAVTVQLPGGE ${ }^{122} \mathrm{R}$ & +0.3 & - & - & $1.9 \times 10^{-9}$ & 6.9 \\
\hline${ }^{105} \mathrm{~K}-{ }^{106} \mathrm{D}:{ }^{102} \mathrm{FEE}[\mathrm{K}][\mathrm{D}]$ GIDYAAVTVQLPGGE ${ }^{122} \mathrm{R}$ & +0.4 & - & - & $3.1 \times 10^{-6}$ & 3.8 \\
\hline${ }^{137} \mathrm{~K}-{ }^{139} \mathrm{E}:{ }^{131}$ QLVASG $[\mathrm{K}] \mathrm{P}[\mathrm{E}]$ SFSGDFLVPSY $\mathrm{Y}^{151} \mathrm{R}$ & +1.4 & 207 & 39 & - & 9.9 \\
\hline${ }^{180} \mathrm{D}-{ }^{186} \mathrm{~K}:{ }^{162} \mathrm{GGSTGYDNAVALPAGGRG[D]EEELQ}[\mathrm{K}] \mathrm{ENN}^{190} \mathrm{~K}$ & +1.1 & 224 & 59 & - & $\mathrm{NA}^{f}$ \\
\hline${ }^{182} \mathrm{E}-{ }^{186} \mathrm{~K}:{ }^{162} \mathrm{GGSTGYDNAVALPAGGRGDE[E]ELQ[K]ENN}{ }^{190} \mathrm{~K}$ & +0.2 & 223 & 59 & $1.0 \times 10^{-5}$ & 9.7 \\
\hline
\end{tabular}

${ }^{a}$ StavroX ${ }^{51}$ and MassMatrix ${ }^{52}$ were used to identify the various cross-linked products. ${ }^{b}$ A significant score: qualifying cross-links have a StavroX score of $>100$ and $>3$ times the FDR. ${ }^{c}$ FDR, the StavroX false discovery rate, represents a score at which the rate of false discovery is $<5 \%{ }^{d} P$ value, calculated by MassMatrix using $\max (\mathrm{pp} 1, \mathrm{pp} 2)$, pptag. ${ }^{e}$ Distances between the corresponding residues in the cyanobacterial PsbO structure of PS II. These residues are not necessarily fully conserved in higher-plant PsbO. ${ }^{4}$ Not applicable, as no corresponding residues are present.

$5 \times 10^{-10}$. The quality of the data used in this work is illustrated in Figure 2. This figure illustrates the mass analysis for the intrachain cross-link involving ${ }^{14} \mathrm{~K}$ and ${ }^{18} \mathrm{E}$, which was the median- $P$ value cross-linked product $\left(P=2.5 \times 10^{-7}\right)$ identified in this study. This peptide exhibits nearly complete $y$ - and $b$-ion series (Figure 2A,B), the exception being that residues that lie between the two cross-linked residues cannot be identified using MassMatrix. A heat map, which visually assists in the identification of cross-linked products in MassMatrix, is also shown (Figure 2C). This cross-linked species was additionally identified with StavroX (Table 1).

Structure of Higher-Plant PsbO. Table 1 summarizes the cross-linked products identified using MassMatrix and StavroX. For the majority of the cross-linked products observed, analogous residue pairs are present in cyanobacterial PsbO. The $\mathrm{C}_{\alpha}-\mathrm{C}_{\alpha}$ distances between these corresponding residue pairs in cyanobacterial PsbO are generally within $12.1 \AA$ (Table 1 ); this was expected and highlights the overall structural similarity between the higher-plant and cyanobacterial PsbO proteins. Only two anomalously long distances were observed. In T. vulcanus, the residues that correspond to the ${ }^{66} \mathrm{~K}-{ }^{234} \mathrm{D}$ cross-linked residues in spinach are residues ${ }^{58} \mathrm{~K}$ and ${ }^{231} \mathrm{E}$. In the crystal structure, the $\alpha$-carbons of these residues are 16.1 $\AA$ apart. This might indicate a modest conformational difference of $\sim 4 \AA$ between the higher-plant and cyanobacterial proteins. The second anomaly is more difficult to explain. In T. vulcanus, the residues that correspond to the ${ }^{97} \mathrm{D}-{ }^{105} \mathrm{~K}$ cross-linked residues in spinach are residues ${ }^{89} \mathrm{D}$ and ${ }^{97} \mathrm{E}$. In the crystal structure, the $\alpha$-carbons of these residues are $22.9 \AA$ apart. This would indicate a rather large conformational (>10 $\AA$ ) difference between the higher-plant and cyanobacterial proteins. Interestingly, these residues flank a domain on the PsbO protein that is resistant to radiolytic modification (see below). At this point in time, we cannot explain this anomaly.

The residues located at the $\mathrm{N}$-terminus of the higher-plant protein $\left({ }^{1} \mathrm{E}-{ }^{10} \mathrm{E}\right)$ are not present in cyanobacterial PsbO. Three cross-linked residue pairs were present in this domain. Additionally, cross-linked residues were located in the vicinity of spinach residues ${ }^{138} \mathrm{P}$ and ${ }^{139} \mathrm{E}$. The eight-residue insertion that forms the cyano loop ${ }^{67}$ in the T. vulcanus PsbO structure lies between ${ }^{138} \mathrm{P}$ and ${ }^{139} \mathrm{E}$ in the higher-plant protein. Finally, crosslinked residue pairs that lie near spinach residues ${ }^{178} \mathrm{R}-{ }^{180} \mathrm{D}$ that are absent in T. vulcanus PsbO were identified. This cross-linking information places constraints on the possible structures that can be assumed by higher-plant PsbO when it is bound to PS II.

Given these distance constraints provided by the observed cross-linked products (Table 1), molecular dynamics refinement can provide useful models for higher-plant PsbO, particularly with respect to its $10 \mathrm{~N}$-terminal amino acid residues, which are not conserved in the cyanobacterial protein. MODELLER ${ }^{57}$ was used to provide the structures shown in Figure 3, which illustrates molecular dynamics structural refinements either in the absence (Figure $3 \mathrm{~A}$ ) or in the presence (Figure 3B) of the EDC-crosslinking distance constraints. In both panels, the 10 lowest-energy structures for PsbO are illustrated in different shades of blue and are aligned with the T. vulcanus protein (colored orange). Without inclusion of the distance constraints, the $\mathrm{N}$-terminus is highly disordered. Inclusion of the distance constraints, however, yields a family of very similar structures, all of which exhibit similar low DOPE scores of approximately $-19500 .^{57}$

It should be noted that secondary structure analysis using the Genesilico Metaserver ${ }^{56}$ of the N-terminal domain of PsbO $\left({ }^{1} \mathrm{E}-{ }^{10} \mathrm{E}\right)$, which is not present in the cyanobacterial protein, indicates that the consensus secondary structure for this region 

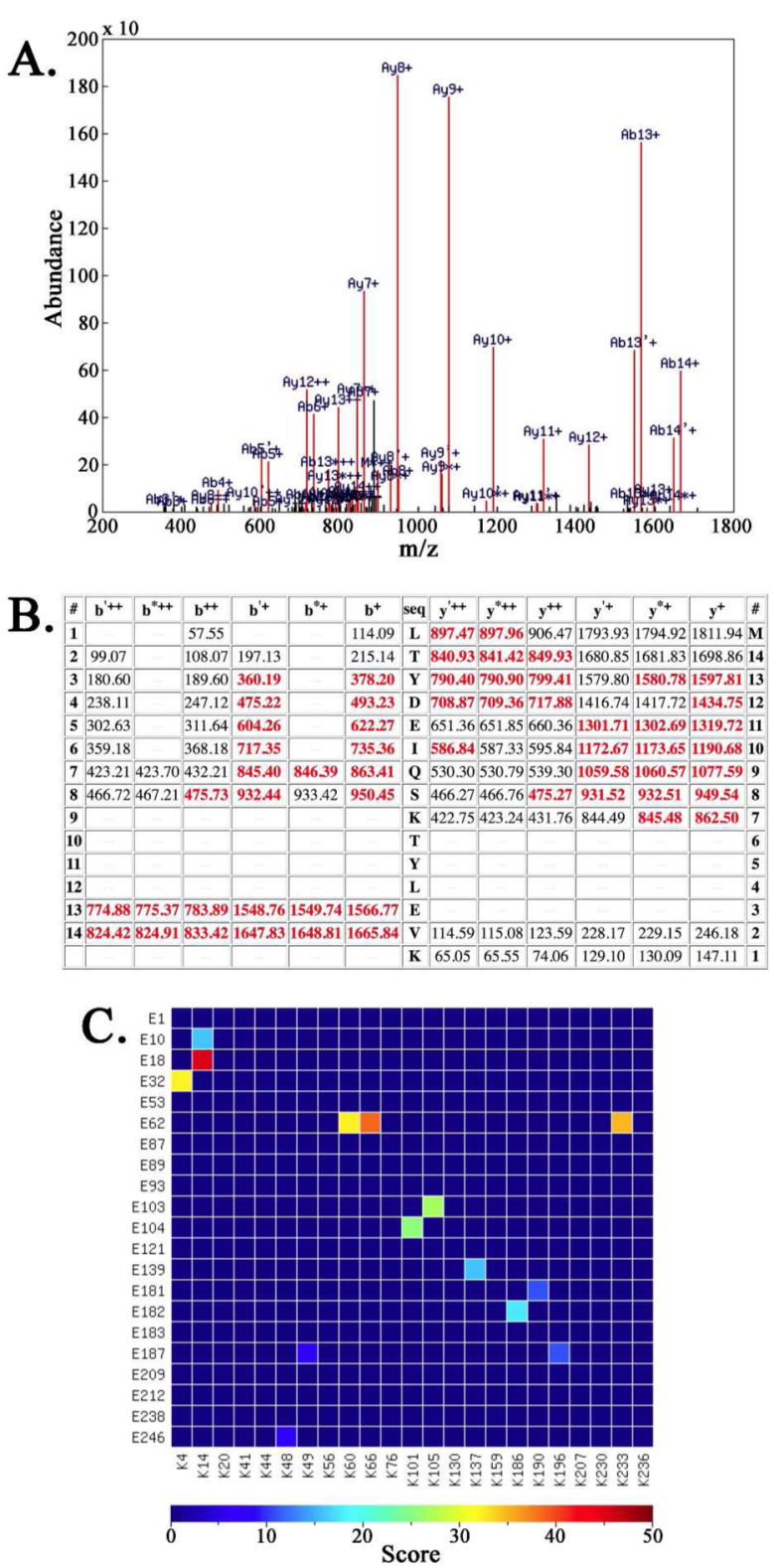

Figure 2. Quality of the mass spectrometry used in this study. Shown are the mass spectrometry data obtained for the median- $P$ value cross-linked product ${ }^{14} \mathrm{~K}-{ }^{18} \mathrm{E}\left(\right.$ Table $\left.1 ; P=2.5 \times 10^{-7}\right)$. (A) Mass spectra obtained for this peptide. Identified ions are colored red and those not identified black. (B) Table of predicted ions from this peptide. Identified ions are colored red and those not identified black. In loop peptides, MassMatrix cannot identify residues lying between the cross-linked residues. Note the nearly complete $y$ - and $b$-ion series obtained. Additionally, $\mathrm{y}^{\prime n+}$ and $\mathrm{b}^{\prime n+}$ ions exhibiting neutral loss of water and $\mathrm{y}^{* n+}$ and $\mathrm{b}^{* n+}$ ions exhibiting neutral loss of ammonia are shown. (C) Heat map that assists in the identification of cross-linked species. The identified peptide is colored red.

contains a short $\alpha$-helix $\left({ }^{7} \mathrm{~T}-{ }^{10} \mathrm{E}\right)$. This program utilizes seven independent secondary structure prediction algorithms. These algorithms uniformly predicted an $\alpha$-helix at this location, and consequently, this was incorporated into the distance-constrained models.

Elucidation of the structure of the N-terminus of PsbO is critical for understanding the function of this component. Early reports indicated that the $16 \mathrm{~N}$-terminal amino acid residues $\left({ }^{1} \mathrm{E}-{ }^{16} \mathrm{Y}\right)$ were required for binding to PS II and efficient oxygen

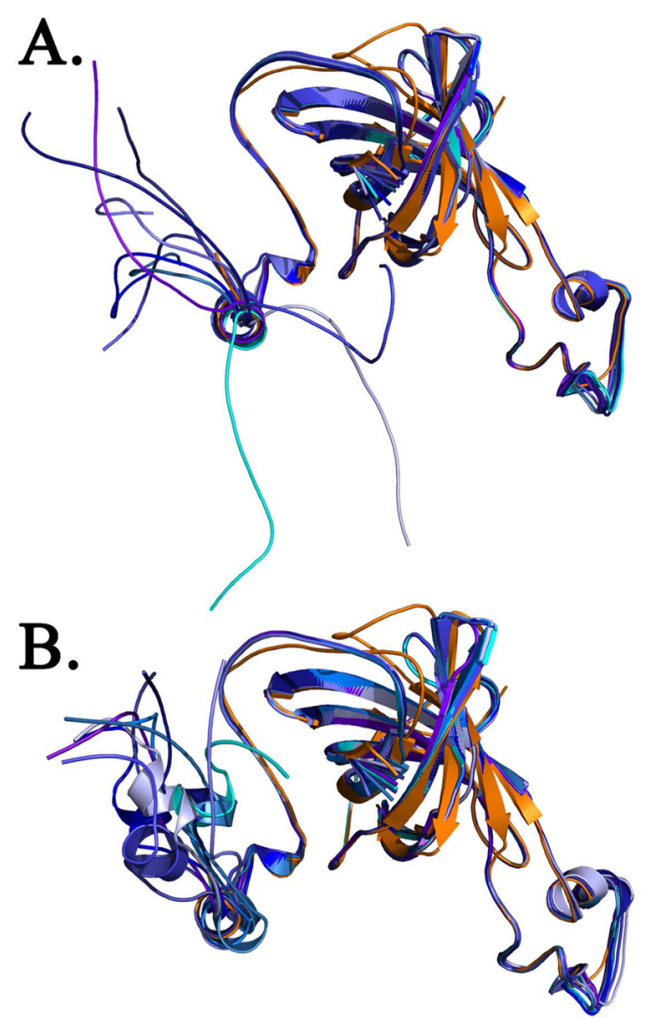

Figure 3. Distance-constrained molecular dynamics refinement for the $\mathrm{N}$-terminus of higher-plant PsbO. Shown are the top 10 models for cases in which (A) no EDC-cross-linking distance constraints are incorporated and (B) EDC distance constraints are incorporated. The individual $\mathrm{PsbO}$ models are shown in various shades of blue and are aligned with cyanobacterial PsbO (colored orange). All models exhibited similar low DOPE scores of approximately -19500 .

evolution in higher plants. ${ }^{68}$ Subsequently, site-directed mutagenesis studies indicated that two binding determinants for PsbO are located in this $\mathrm{N}$-terminal domain (Figure 4). One determinant $\left({ }^{4} \mathrm{~K}-{ }^{10} \mathrm{E}\right)$ is found in higher plants (and green algae), and its deletion abolishes $50 \%$ of the oxygen evolving activity and results in the loss of $50 \%$ of the recombinant PsbO binding. ${ }^{41}$ The second binding determinant $\left({ }^{15} \mathrm{~T}-{ }^{18} \mathrm{E}\right)$ is present in both higher plants and cyanobacteria; its deletion leads to a further loss of PsbO binding and very low oxygen evolution rates. ${ }^{42}$ These authors hypothesized that the deletion of ${ }^{4} \mathrm{~K}-{ }^{10} \mathrm{E}$ prevented one of two copies of PsbO from efficiently binding to the photosystem. The deletion of ${ }^{15} \mathrm{~T}-{ }^{18} \mathrm{E}$ led to the loss of a second copy. The locations of these two experimentally determined binding determinants are illustrated in Figure 4B. It should be noted that the biochemical evidence that suggests that two copies of the PsbO protein are present per PS II monomer in higher plants is quite strong (for in-depth reviews, see refs 13 and 26).

Radiolytic Footprinting of PsbO. Radiolytic footprinting allows the identification of amino acid residues that are exposed to bulk solvent. ${ }^{34-36}$ The ${ }^{\bullet} \mathrm{OH}$ that is produced during radiolysis is extremely reactive and can modify 18 different residues that can be identified by mass spectrometry. ${ }^{36}$ Consequently, radiolytic footprinting is significantly more robust than other chemical modification techniques that can usually label only a few types of residues. ${ }^{64,69-71}$

Table 2 and Figure 5 present the results from the radiolytic footprinting of the PsbO subunit in association with the PS II complex. Mass spectrometry coverage of the PsbO protein was 


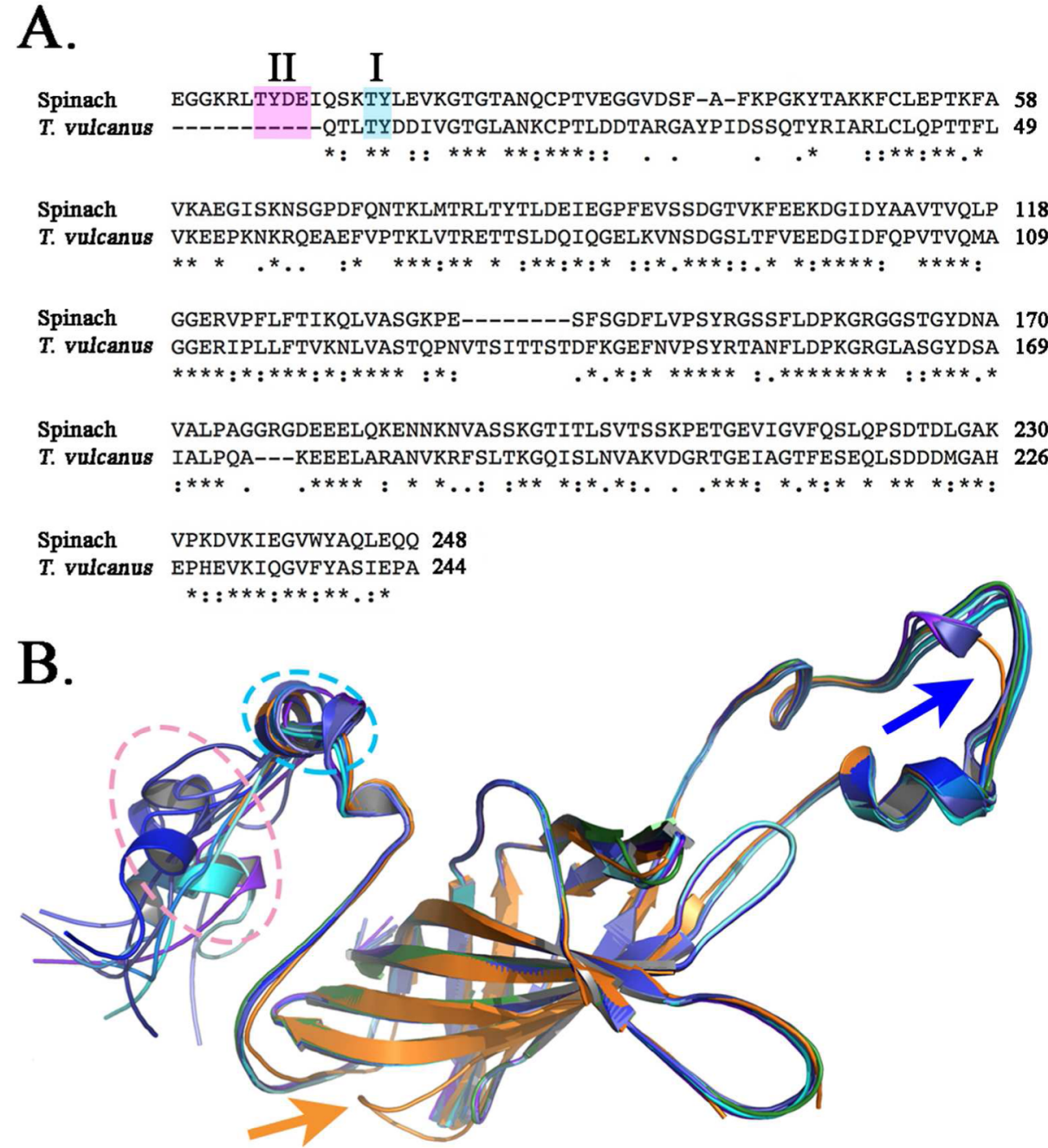

Figure 4. Binding determinants for higher-plant PsbO. (A) Clustal Omega alignment of spinach and T. vulcanus PsbO proteins. This alignment is similar to that presented by Popelkova and Yocum. ${ }^{41,42}$ Binding determinant I (highlighted in cyan) is found in all oxygenic organisms, while binding determinant II (highlighted in magenta) is found only in the green plant lineage. (B) Distance-constrained molecular dynamics refinements for spinach PsbO. Shown are the top 10 models of PsbO presented in different shades of blue. These were aligned with cyanobacterial PsbO (orange, PDB entry 3WU2). Binding determinants I and II are outlined in cyan and magenta dashes, respectively. All of the models illustrated fulfill the EDC distance constraints and exhibit similar low DOPE scores (approximately -19500). The orange arrow indicates the location of the cyano loop (T. vulcanus, ${ }^{131} \mathrm{~N}-{ }^{138} \mathrm{~S}$ ), while the blue arrow indicates the location of the short deletion (spinach, ${ }^{178} \mathrm{R}-{ }^{180} \mathrm{D}$ ) in the cyanobacterial protein.

\section{Table 2. Oxidative Modifications of PsbO $^{a}$}

${ }^{7} \mathrm{~T}+$ stcb,${ }^{8} \mathrm{Y}+$ do, ${ }^{9} \mathrm{D}+$ gam,${ }^{10} \mathrm{E}+\mathrm{ca} /$ gam,${ }^{11} \mathrm{I}+$ go, ${ }^{12} \mathrm{Q}+\mathrm{ca},{ }^{13} \mathrm{~S}+\mathrm{stcb},{ }^{14} \mathrm{R}+$ go, ${ }^{17} \mathrm{~L}+\mathrm{ca} /$ go, ${ }^{18} \mathrm{E}+$ gam, ${ }^{19} \mathrm{~V}+\mathrm{ca},{ }^{20} \mathrm{~K}+\mathrm{ca} / \mathrm{go},{ }^{22} \mathrm{~T}+\mathrm{stcb},{ }^{24} \mathrm{~T}+\mathrm{stcb}$, ${ }^{26} \mathrm{~N}+$ go, ${ }^{27} \mathrm{Q}+\mathrm{ca},{ }^{29} \mathrm{P}+\mathrm{ca},{ }^{30} \mathrm{~T}+$ stcb $,{ }^{31} \mathrm{~V}+\mathrm{ca},{ }^{32} \mathrm{E}+$ gam,${ }^{50} \mathrm{~F}+$ go, ${ }^{53} \mathrm{E}+$ gam,${ }^{55} \mathrm{~T}+$ go, ${ }^{56} \mathrm{~K}+$ ca,${ }^{57} \mathrm{~F}+$ go, ${ }^{60} \mathrm{~K}+$ go, ${ }^{65} \mathrm{~S}+$ stcb $,{ }^{66} \mathrm{~K}+\mathrm{ca},{ }^{88} \mathrm{I}+$ go,

${ }^{89} \mathrm{E}+$ gam, ${ }^{91} \mathrm{P}+\mathrm{ca},{ }^{96} \mathrm{~S}+$ go, ${ }^{97} \mathrm{D}+$ gam,${ }^{99} \mathrm{~T}+$ stcb,${ }^{100} \mathrm{~V}+$ go, ${ }^{101} \mathrm{~K}+$ ca/go, ${ }^{102} \mathrm{~F}+$ go, ${ }^{103} \mathrm{E}+$ ca/gam, ${ }^{104} \mathrm{E}+\mathrm{ca} /$ gam, ${ }^{105} \mathrm{~K}+\mathrm{ca} /$ go, ${ }^{106} \mathrm{D}+\mathrm{ca} /$ gam $/$ go, ${ }^{108} \mathrm{I}+$ ca/go, ${ }^{109} \mathrm{D}+$ gam $/$ go, ${ }^{110} \mathrm{Y}+$ go, ${ }^{116} \mathrm{Q}+$ ca,${ }^{118} \mathrm{P}+$ go, ${ }^{121} \mathrm{E}+$ gam,${ }^{122} \mathrm{R}+$ ca $,{ }^{138} \mathrm{P}+\mathrm{ca},{ }^{139} \mathrm{E}+$ gam,${ }^{140} \mathrm{~S}+$ go/stcb,${ }^{141} \mathrm{~F}+$ do, ${ }^{156} \mathrm{~L}+\mathrm{ca}$,

${ }^{157} \mathrm{D}+$ gam, ${ }^{159} \mathrm{R}+$ go, ${ }^{165} \mathrm{~T}+$ stcb,${ }^{167} \mathrm{Y}+$ do, ${ }^{168} \mathrm{D}+$ gam $/$ do $,{ }^{174} \mathrm{P}+\mathrm{ca},{ }^{178} \mathrm{R}+$ go, ${ }^{180} \mathrm{D}+$ gam, ${ }^{181} \mathrm{E}+$ gam, ${ }^{182} \mathrm{E}+\mathrm{ca},{ }^{183} \mathrm{E}+\mathrm{ca},{ }^{184} \mathrm{~L}+$ gam, ${ }^{185} \mathrm{Q}+$ go, ${ }^{186} \mathrm{~K}+$ ca, ${ }^{187} \mathrm{E}+$ gam, ${ }^{188} \mathrm{~N}+$ gam, ${ }^{207} \mathrm{~K}+$ ca/go, ${ }^{208} \mathrm{P}+$ ca,${ }^{209} \mathrm{E}+$ gam,,${ }^{210} \mathrm{~T}+$ go, ${ }^{212} \mathrm{E}+$ gam, ${ }^{226} \mathrm{D}+$ gam,${ }^{227} \mathrm{~L}+$ ca,${ }^{230} \mathrm{~K}+$ go

${ }^{a}$ MassMatrix was used to identify the locations of oxidative modifications. In some instances, different types of oxidative modifications were observed for a given residue. Key: ca, carbonyl addition, $+13.98 \mathrm{Da}$; do, double oxidation, $+31.99 \mathrm{Da}$; go, general oxidation, $+15.99 \mathrm{Da}$; gam, Glu/Asp decarboxylation, $+30.01 \mathrm{Da}$; stcb, Ser/Thr carbonyl, $-2.02 \mathrm{Da}$. It should be noted that while a total of 12 different types of oxidative modifications were incorporated into the MassMatrix searches, only these five types were actually observed.

$100 \%$ upon integration over all of the irradiation time points $(0,4,8$, and $16 \mathrm{~s})$. Table 2 identifies the residues and types of oxidative modifications observed. The individual time points are not shown; Table 2 and Figure 5 represent a unified set of all of the identified oxidatively modified residues observed in the experiment at all time points.
In Table 2, 77 oxidatively modified PsbO residues were identified. Using modern high-resolution and sensitivity mass spectrometers (FTICR and Orbitrap-class instruments), the oxidative modification of 18 amino acid residues can be detected and identified. ${ }^{36,72}$ Only glycine and alanine remain refractory to radiolytic analysis, because of their low reactivity. As expected, in 


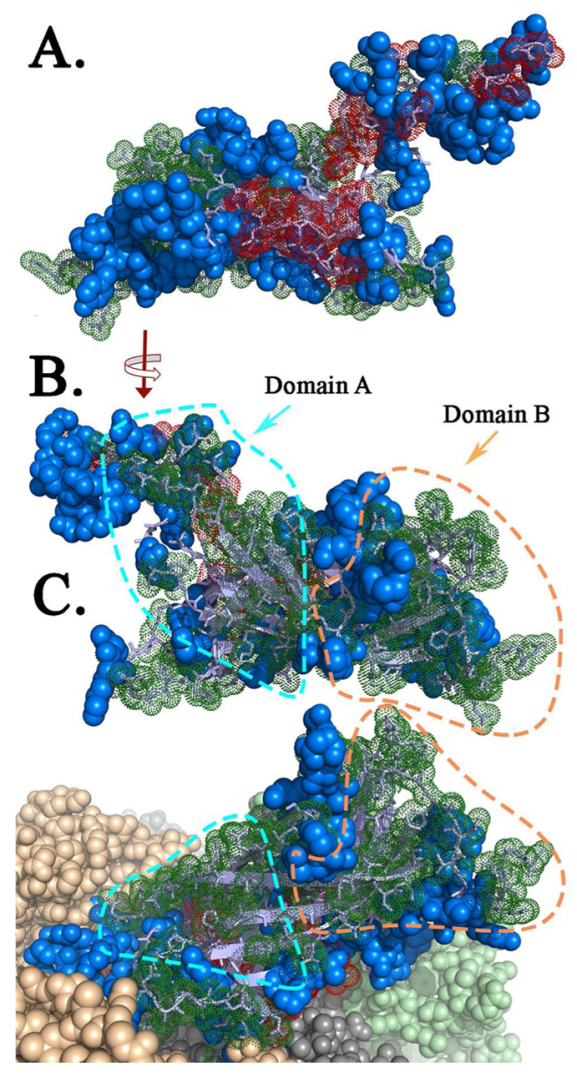

Figure 5. Radiolytic mapping of solvent-exposed domains on higherplant PsbO. Seventy-seven oxidatively modified residues (blue spheres) were identified. These are listed in Table 2 . The mass spectrometry coverage of PsbO was $100 \%$. (A) View of PsbO from the surface of the PS II intrinsic proteins. Residues that were not oxidatively modified and associate with the intrinsic components of the photosystem are shown as red dotted spheres. (B) View of PsbO from the lumen looking down onto PS II. No oxidatively modified residues were identified in the large contiguous lumenally exposed domains labeled domain A (outlined in cyan) and domain B (outlined in orange). Residues that were not oxidatively modified and face the bulk solvent are shown as green dotted spheres. We speculate that these are shielded from oxidative modification by as yet unidentified PS II components. (C) Spinach PsbO shown within the context of cyanobacterial PS II. CP43 is colored green; CP47 is colored brown, and all other subunits are colored gray.

some instances, multiple different oxidative modifications were observed for the same residue.

In Figure 5, the locations of the radiolytic modifications are shown. In Figure 5A, the PsbO protein is viewed from the surface of the intrinsic proteins looking toward the face of $\mathrm{PsbO}$ that interacts with the photosystem. In this view, the domains on PsbO that interact with the intrinsic subunits and are shielded from the bulk solvent and, consequently, radiolytic modification are illustrated. Three shielded regions are evident $\left({ }^{76} \mathrm{~K}-{ }^{87} \mathrm{E}\right.$, ${ }^{149} \mathrm{~S}-{ }^{155} \mathrm{~F}$, and ${ }^{169} \mathrm{~N}-{ }^{173} \mathrm{~L}$ ), and these correspond to regions of cyanobacterial $\mathrm{PsbO}$ that interact with the intrinsic proteins in the cyanobacterial crystal structure $\left({ }^{76} \mathrm{~K}-{ }^{87} \mathrm{E}\right.$ interacts with $\mathrm{CP} 43$ and $\mathrm{D} 1 ;{ }^{149} \mathrm{~S}-{ }^{155} \mathrm{~F}$ interacts with $\mathrm{CP} 43$ and $\mathrm{D} 1 ;{ }^{169} \mathrm{~N}-{ }^{173} \mathrm{~L}$ interacts with CP47 and D2) of Umena et al. ${ }^{4}$

In Figure 5B, the protein is viewed from the lumen, looking down onto the exposed surface of the PsbO protein. While numerous exposed residues are modified, a large contiguous domain that is not susceptible to oxidative modification is evident. This includes a large region wrapping around the $\beta$-barrel. This is not due to the presence of a high proportion of glycyl and alanyl amino acid residues, which cannot be identified using this technique. Approximately $80 \%$ of the residues in this domain would be identifiable after oxidative modification. This compares favorably to the percentage ( $85 \%$ ) that would be identifiable given the standard abundance of amino acids within proteins (Release Notes for UniProtKB/Swiss-Prot data bank, April 2013). In the cyanobacterial crystal structure, these domains do not interact with other PS II subunits, are surface-exposed, and, consequently, should be highly susceptible to radiolytic modification.

The overall pattern of oxidative modifications of higher-plant $\mathrm{PsbO}$ is seen within the context of PS II in Figure 5C. Higherplant PsbO was aligned with the PsbO subunit of T. vulcanus as it appears in the cyanobacterial photosystem (PDB entry $3 \mathrm{WU} 2^{4}$ ). Because the overall fold of higher-plant PsbO and cyanobacterial $\mathrm{PsbO}$ is quite similar (Figure $4 \mathrm{~B}$ ) and because the major intrinsic components of the photosystem that interact with PsbO (D1, $\mathrm{D} 2, \mathrm{CP} 43$, and CP47) are highly conserved, we believe that this model strongly approximates the organization of a single copy of higher-plant PsbO in association with one PS II monomer. What is clear from panels $\mathrm{B}$ and $\mathrm{C}$ of Figure 5 is that large portions of the higher-plant PsbO protein, which by analogy to the cyanobacterial subunit should be exposed to the bulk solvent, are not observed to be radiolytically modified.

A number of hypotheses could explain this observation. It is formally possible that higher-plant PsbO undergoes a large conformational change upon being associated with PS II, shielding the unmodified residues from the bulk solvent and, consequently, radiolytic modification. In our view, this is highly unlikely and would require unprecedented conformational flexibility of the $\beta$-barrel of the protein. Additionally, it would require that the overall architecture of higher-plant PsbO be significantly different from that of the cyanobacterial protein. No evidence of this exists.

A second hypothesis is that the unmodified domains represent regions on the PsbO protein that are shielded by interaction with other PS II subunits. Several possibilities exist. The unmodified PsbO domains could be regions that interact with PsbP and PsbQ. Several investigators have examined the interaction of these subunits with the photosystem. In cyanobacteria, Liu et al. ${ }^{31}$ proposed a binding domain for CyanoQ at the lumenal PS II dimer interface. These authors observed cross-linking between $\mathrm{PsbO}$ and $\mathrm{Cyano \textrm {Q }}$ that strongly supported their hypothesis. If PsbQ were positioned in an analogous location in higher-plant PS II, this could explain the lack of radiolytic modification in domain A (Figure 5B,C), which lies near the PS II dimer interface. One such model was previously proposed for higherplant PS II. ${ }^{33}$ It should be noted that other investigators have presented alternative models for the location of higher-plant PsbQ, suggesting that it lies at the periphery of PS II and is closely associated with CP43. ${ }^{11,12,32,33}$ In these models, PsbQ was suggested to be located in a position roughly similar to that of $\mathrm{PsbQ}^{\prime}$ in the red alga C. caldarium. ${ }^{25}$ If this positioning is correct for higher-plant PsbQ then the observed absence of modifcations in domain A (Figure 5B,C) cannot be explained. In any event, the presence of unmodified residues in domain $B$ (Figure $5 B, C$ ) cannot be attributed to the presence of PsbQ in any of the models that have been presented previously.

It also appears very unlikely that PsbP could occupy domain B. In higher-plant PS II membranes, Ido et al. ${ }^{29,32}$ observed EDC cross-linking between PsbP: ${ }^{1} \mathrm{~A}$ and PsbE: ${ }^{57} \mathrm{E}$, indicating that these residues are in van der Waals contact. The closest approach between PsbE: ${ }^{57} \mathrm{E}$ and domain $\mathrm{B}$ is $>80 \AA$, which would appear 
to preclude the association of $\mathrm{PsbP}$ with domain $\mathrm{B}$ of $\mathrm{PsbO}$ (Figure 5B,C).

Other components have been reported to be associated with PS II membranes and core complexes. These include catalase and polyphenol oxidase, ${ }^{73}$ TL29, ${ }^{7,75}$ TLP18.3 (Psb32), ${ }^{75,76}$ and a YCF39-like protein. ${ }^{75}$ It is possible that these (and perhaps other) components are associated with PS II membranes but have generally escaped detection, possibly because of the substoichiometric abundance or unusually poor protein staining. The presence of a substoichiometric component in association with domain B (Figure 5B,C), for instance, could reduce the amount of oxidative modification in the domain to below levels that can be detected by mass analysis.

Clearly, one of the most intriguing possibilities is that a second copy of PsbO may associated with domain B. While the biochemical evidence of the presence of a second copy of PsbO within the PS II monomer is very strong, ${ }^{13,26}$ it must be stressed that no direct structural evidence of a second copy of PsbO has been forthcoming. At this time, we cannot distinguish between these various possibilities.

\section{CONCLUSIONS}

In this work, we have provided new information concerning structural features of the PsbO protein from higher plants while it is in association with PS II membranes. The location and organization of the $\mathrm{N}$-terminal 10 -amino acid residue extension that is present in higher plants, but not in cyanobacteria, have been examined and structural models for this domain presented. This region appears to be instrumental in the binding of $\mathrm{PsbO}$ in higher plants. ${ }^{41,42}$ Additionally, radiolytic footprinting experiments indicate that large contiguous domains on the surface of $\mathrm{PsbO}$ are resistant to oxidative modification and, consequently, appear to be shielded from the bulk solvent by as yet unidentified PS II components. Ongoing investigations are underway in an attempt to identify the species responsible for this observation.

\section{NOTE ADDED IN PROOF}

Recently, Wei et al. (2016) (Nature DOI: 10.1038/nature18020) have presented a cryo-EM structure of an inactive spinach PS II-LHCII supercomplex at $3.2 \AA$ resolution. The $\mathrm{N}$-terminus of the $\mathrm{PsbO}$ protein that is presented in this structure is highly congruent to the structure presented in this communication.

\section{AUTHOR INFORMATION}

\section{Corresponding Author}

*Department of Biological Sciences, Louisiana State University, Baton Rouge, LA 70803. E-mail: btbric@lsu.edu. Phone: (225) 578-1555.

\section{Funding}

This work was supported by the U.S. Department of Energy, Office of Basic Energy Sciences (DE-FG02-09ER20310 to T.M.B. and L.K.F.). H.D.B. was supported by the Louisiana Governor's Biotechnology Initiative. L.S. was supported by the University of Cincinnati.

\section{Notes}

The authors declare no competing financial interest.

\section{ABBREVIATIONS}

DOPE, discrete optimized protein energy; EDC, 1-ethyl-3-(3dimethylaminopropyl) carbodiimide; LiDS, lithium dodecyl sulfate; PAGE, polyacrylamide gel electrophoresis; PS I, Photosystem I; PS II, Photosystem II.

\section{REFERENCES}

(1) Cardona, T., Sedoud, A., Cox, N., and Rutherford, A. W. (2012) Charge separation in Photosystem II: A comparative and evolutionary overview. Biochim. Biophys. Acta, Bioenerg. 1817, 26-43.

(2) Vinyard, D. J., Ananyev, G. M., and Dismukes, G. C. (2013) Photosystem II: The reaction center of oxygenic photosynthesis. Annu. Rev. Biochem. 82, 577-606.

(3) Yano, J., and Yachandra, V. (2014) $\mathrm{Mn}_{4} \mathrm{Ca}$ cluster in photosynthesis: Where and how water is oxidized to dioxygen. Chem. Rev. 114, 4175-4205.

(4) Umena, Y., Kawakami, K., Shen, J.-R., and Kamiya, N. (2011) Crystal structure of oxygen-evolving Photosystem II at a resolution of 1.9 Å. Nature 473, 55-60.

(5) Burnap, R. L., and Sherman, L. A. (1991) Deletion mutagenesis in Synechocystis sp. PCC 6803 indicates that the Mn-stabilizing protein of Photosystem II is not essential for oxygen evolution. Biochemistry 30, $440-446$.

(6) Bricker, T. M. (1992) Oxygen evolution in the absence of the 33 $\mathrm{kDa}$ manganese-stabilizing protein. Biochemistry 31, 4623-4628.

(7) Bricker, T. M., and Frankel, L. K. (2011) Auxiliary functions of the PsbO, PsbP and PsbQ proteins of higher plant Photosystem II: A critical analysis. J. Photochem. Photobiol., B 104, 165-178.

(8) Fagerlund, R. D., and Eaton-Rye, J. J. (2011) The lipoproteins of cyanobacterial Photosystem II. J. Photochem. Photobiol., B 104, 191-203.

(9) Bricker, T. M., Roose, J. L., Fagerlund, R. D., Frankel, L. K., and Eaton-Rye, J. J. (2012) The extrinsic proteins of Photosystem II. Biochim. Biophys. Acta, Bioenerg. 1817, 121-142.

(10) Bricker, T. M., Roose, J. L., Zhang, P., and Frankel, L. K. (2013) The PsbP family of proteins. Photosynth. Res. 116, 235-250.

(11) Ifuku, K. (2014) The PsbP and PsbQ family proteins in the photosynthetic machinery of chloroplasts. Plant Physiol. Biochem. 81, 108-114.

(12) Roose, J. L., Frankel, L. K., Mummadisetti, M. P., and Bricker, T. M. (2016) The extrinsic proteins of Photosystem II: Update. Planta 243, 889-208.

(13) Bricker, T. M., and Frankel, L. K. (1998) The structure and function of the $33 \mathrm{kDa}$ extrinsic protein of Photosystem II. A critical review. Photosynth. Res. 56, 157-173.

(14) Ifuku, K., Yamamoto, J., Ono, T.-A., Ishihara, S., and Sato, F. (2005) PsbP protein, but not PsbQ protein, is essential for the regulation and stabilization of Photosystem II in higher plants. Plant Physiol. 139, 1175-1184.

(15) Yi, X., McChargue, M., Laborde, S. M., Frankel, L. K., and Bricker, T. M. (2005) The manganese-stabilizing protein is required for Photosystem II assembly/stability and photoautotrophy in higher plants. J. Biol. Chem. 280, 16170-16174.

(16) Yi, X., Liu, H., Hargett, S. R., Frankel, L. K., and Bricker, T. M. (2007) The PsbP protein is required for Photosystem II complex assembly/stability and photoautotrophy in Arabidopsis thaliana. J. Biol. Chem. 282, 24833-24841.

(17) Yi, X., Hargett, S. R., Frankel, L. K., and Bricker, T. M. (2009) The PsbP protein, but not the PsbQ protein, is required for normal thylakoid membrane architecture in Arabidopsis thaliana. FEBS Lett. 583, 21422147.

(18) Burnap, R. L., Shen, J.-R., Jursinic, P. A., Inoue, Y., and Sherman, L. A. (1992) Oxygen yield and thermoluminescence characteristics of a cyanobacterium lacking the manganese-stabilizing protein of Photosystem II. Biochemistry 31, 7404-7410.

(19) Zouni, A., Witt, H.-T., Kern, J., Fromme, P., Krauss, N., Saenger, W., and Orth, P. (2001) Crystal structure of Photosystem II from Synechococcus elongatus at $3.8 \AA$ Åsolution. Nature 409, 739-743.

(20) Kamiya, N., and Shen, J.-R. (2003) Crystal structure of oxygenevolving Photosystem II from Thermosynechococcus vulcanus at $3.7 \AA$ resolution. Proc. Natl. Acad. Sci. U. S. A. 100, 98-103.

(21) Ferreira, K. N., Iverson, T. M., Maghlaoui, K., Barber, J., and Iwata, S. (2004) Architecture of the photosynthetic oxygen-evolving center. Science 303, 1831-1838. 
(22) Loll, B., Kern, N., Saenger, W., Zouni, A., and Biesiadka, J. (2005) Towards complete cofactor arrangement in the $3.0 \AA$ resolution structure of Photosystem II. Nature 438, 1040-1044.

(23) Guskov, A., Kern, J., Gabdulkhakov, A., Broser, M., Zouni, A., and Saenger, W. (2009) Cyanobacterial Photosystem II at $2.9 \AA$ A resolution and the roles of quinones, lipids, channels and chloride. Nat. Struct. Mol. Biol. 16, 334-342.

(24) Suga, M., Akita, F., Hirata, K., Ueno, G., Murakami, H., Nakajima, Y., Shimizu, T., Yamashita, K., Yamamoto, M., Ago, H., and Shen, J. R. (2014) Native structure of Photosystem II at 1.95 angstrom resolution viewed by femtosecond X-ray pulses. Nature 517, 99-103.

(25) Ago, H., Adachi, H., Umena, Y., Tashiro, T., Kawakami, K., Kamiya, N., Tian, L., Han, G., Kuang, T., Liu, Z., Wang, F., Zou, H., Enami, I., Miyano, M., and Shen, J.-R. (2016) Novel features of eukaryotic Photosystem II revealed by its crystal structure analysis from a red alga. J. Biol. Chem. 291, 5676-5687.

(26) Popelkova, H., and Yocum, C. F. (2011) PsbO, the manganesestabilizing protein: Analysis of the structure-function relations that provide insights into its role in Photosystem II. J. Photochem. Photobiol., B 104, 179-190.

(27) Singh, P., Panchaud, A., and Goodlett, D. R. (2010) Chemical cross-Linking and mass spectrometry as a low-resolution protein structure determination technique. Anal. Chem. 82, 2636-2642.

(28) Bricker, T. M., Mummadisetti, M. P., and Frankel, L. K. (2015) Recent advances in the use of mass spectrometry to examine structure/ function relationships in Photosystem II. J. Photochem. Photobiol., B 152, 227-246.

(29) Ido, K., Kakiuchi, S., Uno, C., Nishimura, T., Fukao, Y., Noguchi, T., Sato, F., and Ifuku, K. (2012) The conserved His-144 in the PsbP protein is important for the interaction between the PsbP N-terminus and the Cyt $b_{559}$ subunit of Photosystem II. J. Biol. Chem. 287, 2637726387.

(30) Liu, H., Zhang, H., Niedzwiedzki, D. M., Prado, M., He, G., Gross, M. L., and Blankenship, R. E. (2013) Phycobilisomes supply excitations to both photosystems in a megacomplex in cyanobacteria. Science 342, 1104-1107.

(31) Liu, H., Zhang, H., Weisz, D. A., Vidavsky, I., Gross, M. L., and Pakrasi, H. B. (2014) MS-based cross-linking analysis reveals the location of the PsbQ protein in cyanobacterial Photosystem II. Proc. Natl. Acad. Sci. U. S. A. 111, 4638-4643.

(32) Ido, K., Nield, J., Fukao, Y., Nishimura, T., Sato, F., and Ifuku, K. (2014) Cross-linking evidence for multiple interactions of the PsbP and PsbQ proteins in a higher plant Photosystem II supercomplex. J. Biol. Chem. 289, 20150-20157.

(33) Mummadisetti, M. P., Frankel, L. K., Bellamy, H., Sallans, L., Goettert, J. S., Brylinski, M., Limbach, P. A., and Bricker, T. M. (2014) Use of protein cross-linking and radiolytic footprinting to elucidate PsbP and PsbQ interactions within higher plant Photosystem II. Proc. Natl. Acad. Sci. U. S. A. 111, 16178-16183.

(34) Takamoto, K., and Chance, M. R. (2006) Radiolytic protein footprinting with mass spectrometry to probe the structure of macromolecular complexes. Annu. Rev. Biophys. Biomol. Struct. 35, 251-276.

(35) Orban, T., Gupta, S., Palczewski, K., and Chance, M. R. (2010) Visualizing water molecules in transmembrane proteins using radiolytic labeling methods. Biochemistry 49, 827-834.

(36) Kiselar, J. G., and Chance, M. R. (2010) Future directions of structural mass spectrometry using hydroxyl radical footprinting. J. Mass Spectrom. 45, 1373-1382.

(37) Guan, J. Q., Vorobiev, S., Almo, S. C., and Chance, M. R. (2002) Mapping the G-actin binding surface of cofilin using synchrotron radiation. Biochemistry 41, 5765-5775.

(38) Liu, R., Guan, J. Q., Zak, O., Aisen, P., and Chance, M. (2003) Structural reorganization of the transferrin c-lobe and transferrin receptor upon complex formation:the c-lobe binds to the receptor helical domain. Biochemistry 42, 12447-12454.

(39) Angel, T. E., Gupta, S., Jastrzebska, B., Palczewski, K., and Chance, M. (2009) Structural waters define a functional channel mediating activation of the GPCR, rhodopsin. Proc. Natl. Acad. Sci. U. S. A. 106, 14367-14372.

(40) Frankel, L. K., Sallans, L., Bellamy, H., Goettert, J. S., Limbach, P. A., and Bricker, T. M. (2013) Radiolytic mapping of solvent contact surfaces in Photosystem II of higher plants: experimental identification of putative water channels within the photosystem. J. Biol. Chem. 288, 23565-23572.

(41) Popelkova, H., Im, M. M., D’Auria, J., Betts, S. D., LydakisSimantiris, N., and Yocum, C. F. (2002) N-terminus of the Photosystem II manganese-stabilizing protein: effects of sequence elongation and truncation. Biochemistry 41, 2702-2711.

(42) Popelkova, H., Im, M. M., and Yocum, C. F. (2002) N-terminal truncations of the manganese-stabilizing protein identify two amino acid sequences required for binding of the eukaryotic protein to Photosystem II and reveal the absence of one binding-related sequence in cyanobacteria. Biochemistry 41, 10038-10045.

(43) Berthold, D. A., Babcock, G. T., and Yocum, C. F. (1981) A highly resolved oxygen-evolving Photosystem II preparation from spinach thylakoid membranes. FEBS Lett. 134, 231-234.

(44) Arnon, D. I. (1949) Copper enzymes in isolated chloroplasts. Polyphenol oxidase in Beta vulgaris. Plant Physiol. 24, 1-15.

(45) Smith, P. K., Krohn, R. I., Hermanson, G. T., Mallia, A. K., Gartner, F. H., Provenzano, M. D., Fujimoto, E. K., Goeke, N. M., Olson, B. J., and Klenk, D. C. (1985) Measurement of protein using bicinchoninic acid. Anal. Biochem. 150, 76-85.

(46) Delepelaire, P., and Chua, N. H. (1979) Lithium dodecyl sulfate/ polyacrylamide gel electrophoresis of thylakoid membranes at 4 degrees C: Characterizations of two additional chlorophyll $a$-protein complexes. Proc. Natl. Acad. Sci. U. S. A. 76, 111-115.

(47) Sun, G., and Anderson, V. E. (2004) Prevention of artifactual protein oxidation generated during sodium dodecyl sulfate-gel electrophoresis. Electrophoresis 25, 959-965.

(48) Frankel, L. K., Sallans, L., Limbach, P. A., and Bricker, T. M. (2012) Identification of oxidized amino acid residues in the vicinity of the $\mathrm{Mn}_{4} \mathrm{CaO}_{5}$ cluster of Photosystem II: Implications for the identification of oxygen channels within the photosystem. Biochemistry 51, 6371-6377.

(49) Rabilloud, T., Vincon, M., and Garin, J. (1995) Micropreparative one- and two-dimensional electrophoresis: Improvement with new photopolymerization systems. Electrophoresis 16, 1414-1422.

(50) Xu, H., and Freitas, M. A. (2007) A mass accuracy sensitive probability based scoring algorithm for database searching of tandem mass spectrometry data. BMC Bioinf. 8, 133-137.

(51) Xu, H., and Freitas, M. A. (2009) MassMatrix: A database search program for rapid characterization of proteins and peptides from tandem mass spectrometry data. Proteomics 9, 1548-1555.

(52) Götze, M., Pettelkau, J., Schaks, S., Bosse, K., Ihling, C. H., Krauth, F., Fritzsche, R., Kühn, U., and Sinz, A. (2012) StavroX-a software for analyzing crosslinked products in protein interaction studies. J. Am. Soc. Mass Spectrom. 23, 76-87.

(53) Xu, G., and Chance, M. R. (2005) Radiolytic modification and reactivity of amino acid residues serving as structural probes for protein footprinting. Anal. Chem. 77, 4549-4555.

(54) Sievers, F., Wilm, A., Dineen, D. G., Gibson, T. J., Karplus, K., Li, W., Lopez, R., McWilliam, H., Remmert, M., Söding, J., Thompson, J. D., and Higgins, D. G. (2011) Fast, scalable generation of high-quality protein multiple sequence alignments using Clustal Omega. Mol. Syst. Biol. 7, 539.

(55) Arnold, K., Bordoli, L., Kopp, J., and Schwede, T. B. (2006) The SWISS-MODEL Workspace: A web-based environment for protein structure homology modelling. Bioinformatics 22, 195-201.

(56) Kurowski, M. A., and Bujnicki, J. M. (2003) GeneSilico protein structure prediction meta-server. Nucleic Acid Res. 31, 3305-3307.

(57) Eswar, N., Webb, B., Marti-Renom, M. A., Madhusudhan, M. S., Eramian, D., Shen, M.-Y., Pieper, U., and Sali, A. (2007) Comparative protein structure modeling using MODELLER. In Current Protocols in Protein Science, pp 2.9.1-2.9.31, Wiley Publishers, New York.

(58) Kunkel, G. R., Mehrabian, M., and Martinson, H. G. (1981) Contact-site cross-linking reagents. Mol. Cell. Biochem. 34, 3-13. 
(59) Grabarek, Z., and Gergely, J. (1990) Zero-length crosslinking with the use of active esters. Anal. Biochem. 185, 131-135.

(60) Rozbesky, D., Man, P., Kavan, D., Chmelik, J., Cerny, J., Bezouska, K., and Novak, P. (2012) Chemical crosslinking and H/D exchange for fast refinement of protein crystal structure. Anal. Chem. 84, 867-870.

(61) Sriswasdi, S., Harper, S. L., Tang, H.-Y., and Speicher, D. W. (2014) Enhanced identification of zero-length chemical crosslinks using label-free quantitation and high-resolution fragment ion spectra. $J$. Proteome. Res. 13, 898-914.

(62) Laskowski, R. A., MacArthur, M. W., Moss, D. S., and Thornton, J. M. (1993) PROCHECK: a program to check the stereochemical quality of protein structures. J. Appl. Crystallogr. 26, 283-291.

(63) Lovell, S. C., Davis, I. W., Arendall, W. B., III, de Bakker, P. I. W., Word, J. M., Prisant, M. G., Richardson, J. S., and Richardson, D. C. (2003) Structure validation by $\mathrm{C} \alpha$ geometry: $\phi, \psi$ and $\mathrm{C} \beta$ deviation. Proteins: Struct., Funct., Genet. 50, 437-450.

(64) Frankel, L. K., Cruz, J. A., and Bricker, T. M. (1999) The role of carboxylic acid residues on the manganese-stabilizing protein in its binding to Photosystem II. Biochemistry 38, 14271-14278.

(65) Bricker, T. M., Odom, W. R., and Queirolo, C. B. (1988) Close association of the $33 \mathrm{kDa}$ extrinsic protein with the apoprotein of $\mathrm{CPa}-1$ in Photosystem II. FEBS Lett. 231, 111-117.

(66) Odom, W., and Bricker, T. M. (1992) Interaction of CPa-1 with the manganese-stabilizing protein of Photosystem II: Identification of domains cross-linked by 1-ethyl-3-[3-(dimethylamino) propyl]carbodiimide. Biochemistry 31, 5616-5620.

(67) de Las Rivas, J., and Barber, J. (2004) Analysis of the structure of the PsbO protein and its implications. Photosynth. Res. 81, 329-343.

(68) Eaton-Rye, J. J., and Murata, N. (1989) Evidence that the aminoterminus of the $33 \mathrm{kDa}$ extrinsic protein is required for binding to the Photosystem II complex. Biochim. Biophys. Acta, Bioenerg. 977, 219-226.

(69) Frankel, L. K., and Bricker, T. M. (1990) Mapping of NHSbiotinylation sites and the epitope of the monoclonal antibody FAC2 on the apoprotein of CPa-1, Vol. I, Kluwer Academic Publishers, Dordrecht, The Netherlands.

(70) Frankel, L. K., and Bricker, T. M. (1995) Interaction of the $33 \mathrm{kDa}$ extrinsic protein with Photosystem II: identification of domains on the $33 \mathrm{kDa}$ protein that are shielded from NHS biotinylation by Photosystem II. Biochemistry 34, 7492-7497.

(71) Meades, G. D., McLachlan, A., Sallans, L., Limbach, P. A., Frankel, L. K., and Bricker, T. M. (2005) Association of the $17 \mathrm{kDa}$ extrinsic protein with Photosystem II in higher plants. Biochemistry 44, 1521615221.

(72) Xu, G., and Chance, M. R. (2007) Hydroxyl radical-mediated modification of proteins as probes for structural proteomics. Chem. Rev. 107, 3514-3543.

(73) Sheptovitsky, Y. G., and Brudvig, G. W. (1996) Isolation and characterization of spinach Photosystem II membrane-associated catalase and polyphenol oxidase. Biochemistry 35, 16255-16263.

(74) Granlund, I., Storm, P., Schubert, M., García-Cerdán, J. G., Funk, C., and Schröder, W. P. (2009) The TL29 protein is lumen located, associated with PSII and not an ascorbate peroxidase. Plant Cell Physiol. 50, 1898-1910.

(75) Tomizioli, M., Lazar, C., Brugiere, S., Burger, T., Salvi, D., Gatto, L., Moyet, L., Breckels, L. M., Hesse, A.-M., Lilley, K. S., SeigneurinBerny, D., Finazzi, G., Rolland, N., and Ferro, M. (2014) Deciphering thylakoid sub-compartments using a mass spectrometry-based approach. Mol. Cell. Proteomics 13, 2147-2167.

(76) Pagliano, C., Chimirri, F., Saracco, G., Marsano, F., and Barber, J. (2011) One-step isolation and biochemical characterization of a highly active plant PSII monomeric core. Photosynth. Res. 108, 33-46. 